Paediatrician's decision regarding identifying/conducting medicals has been proposed.

\section{G51(P) A REVIEW OF CHILD SEXUAL ABUSE (CSA) REPORTS}

${ }^{1} S$ Deepak, ${ }^{2} \mathrm{C}$ Teh, ${ }^{2} \mathrm{~L}$ Adamson. ${ }^{1}$ Paediatrics, East Midlands Paediatric Trainee, Nottingham, UK; ${ }^{2}$ Community Paediatrics, Derbyshire Health Care NHS Foundation Trust, Derby, UK

\subsection{6/archdischild-2015-308599.50}

Background Few areas of paediatrics have expanded so rapidly in clinical importance as that of sexual abuse of children. What Kempe called a "hidden paediatric problem"1 in 1977 is certainly less hidden at present. The NSPCC statistics April 2014 showed 1 in 20 children have been sexually abused. 5\% of all the children on child protection registers or the subject of child protection plans in the UK were under a category of sexual abuse. Childhood sexual abuse has been correlated with long term morbidities like mental health problems and sexual and relationship problems. So this is a significant public health problem.

Aim We aimed to gain more knowledge on the CSA (child sexual abuse) examination findings in particular the anal findings, the demographics and to find out the prevalence of significant positive findings.

Methodology We carried out a retrospective analysis of CSA reports of children who underwent CSA examination during the 2 year period - April 2011 to April 2013. The electronic reports were accessed following formal permission from the trust.

Findings Majority of the children who underwent CSA examination are females (Figure 1). Only a small proportion of boys were examined. Most of the children were arranged to have the examination following disclosure (Table 1). Nearly half of the female children were noted to have some significant findings; however some of them were conclusive of sexual activity rather than abuse. Only $8.8 \%$ of children had positive anal findings and $54 \%$ had consistent history.

Conclusion Sexual abuse presents in many ways and because children who are sexually abused generally are coerced into secrecy, a high level of suspicion may be required to recognise the problem. Only a small proportion of children were noted to have clinical anal findings, so a detailed history taking is vital.

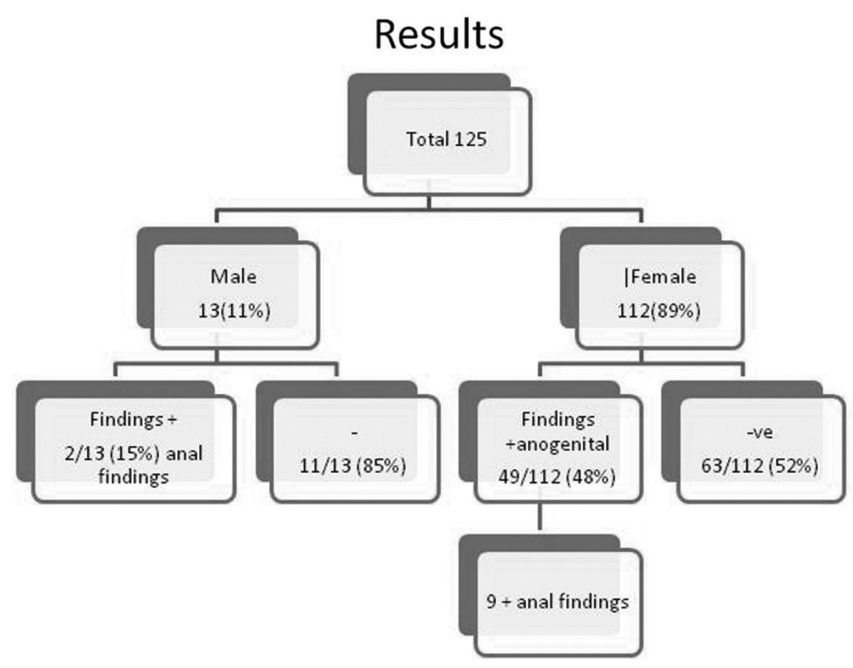

Abstract G51(P) Figure 1 Results of examination following disclosure
Abstract G51(P) Table 1 Reason for CSA examination

\begin{tabular}{|c|c|}
\hline Disclosure & 102 \\
\hline Sibling disclosure & 7 \\
\hline 3rd party concerns & 4 \\
\hline Sexualized behaviour & 2 \\
\hline Porn website pictures & 2 \\
\hline Hitting on bottom & 1 \\
\hline Recurrent Vulvovaginitis & 2 \\
\hline Genital Bleeding & 1 \\
\hline Anal warts & 2 \\
\hline Extreme distress during & 2 \\
\hline
\end{tabular}

\section{G52(P) EVALUATING A SAFEGUARDING PEER REVIEW AND REFLECTIVE SUPERVISION INTERVENTION: EXPLORING PAEDIATRICIANS' PARTICIPATION AND LEARNING}

1,2,3BJA Stewart, 'EL Baker, ' $U$ Venkatesh, ${ }^{1} \mathrm{~J}$ Hourigan, ${ }^{2}$ EJ Wyllie, ${ }^{3}$ RK O'Rourke. ${ }^{1}$ Child Health, York Teaching Hospital NHS Foundation Trust, York, UK; ${ }^{2}$ Designated Professionals Team, North Yorkshire and York Clinical Commissioning Groups, Scarborough, UK; ${ }^{3}$ School of Education, University of Leeds, Leeds, UK

\subsection{6/archdischild-2015-308599.51}

Aims To establish regular peer review and reflective supervision for paediatricians at both sites of an NHS Trust for a six month period and evaluate participation and learning.

Methods An action research methodology was chosen. Morrison's $4 \times 4 \times 4$ reflective supervision model was selected because of its focus of improving safeguarding outcomes for children. New documentary output was developed for peer review sessions. To support participation, peer review and supervision sessions were scheduled during monthly clinical governance halfdays. Attendance at clinical governance sessions is expected for all available paediatricians. Participation in the evaluation of learning was optional. There are 21 paediatricians permanently employed by the Trust. Their participation, any resultant learning and impact was to be explored through examination of documentary outputs from the sessions including attendance registers and from semi-structured interviews. This service evaluation project was registered with the NHS organisation. The evaluation of learning has approval from a university ethics committee.

Results Experienced supervisors were secured and a steering group established. Six sessions were planned at each site beginning with supervisee training for reflective supervision. Then there was to be alternating sessions of reflective supervision or peer review at each site. For the site with 13 paediatricians, six $(6 / 13,46.2 \%)$ were present for training. Of the subsequent five sessions, only one session has taken place. There were four attendees $(4 / 13,30.8 \%)$ at the reflective supervision session, only two of whom had attended the training. Four of the sessions did not take place. For the site with 8 paediatricians, three $(3 / 8,37.5 \%)$ attended training and none of the five planned sessions happened. Of the nine missed sessions, analysis indicates that unavailability of the Named Doctors for Child Protection accounted for four missed sessions, unavailability of other paediatricians for an additional four and an administrative error for one. The details of the barriers to participation will be presented.

Conclusions Scheduling peer review and reflective supervision during clinical governance half-days did not secure 